\title{
Parkinson hastalığında nötrofil/lenfosit oranlarının değerlendirilmesi
}

\author{
The evaluation of neutrophil/lymphocyte ratio in Parkinson's disease
}

Fatma Genç, Abidin Erdal

Gönderilme tarihi:25.12.2018

Kabul tarihi:01.02.2019

Özet

Amaç:Parkinson Hastalığı, kronik inflamasyonun patogenezinde rol oynadığı düşünülen nörodejeneratif bir hastalıktır. Nötrofil/lenfosit oranı ise periferal inflamasyonu gösteren bir belirteçtir. Bu çalışmada nötrofil/lenfosit oranı ile Parkinson hastalığının evresi, süresi ve subtipleri arasındaki ilişkinin araştırılması amaçlanmıştır.

Gereç ve Yöntem:Birleşik Krallık Parkinson Hastalığı Derneği Beyin Bankası kriterlerine göre tanı almış 90 hasta geriye dönük olarak değerlendirilerek, demografik verileri, kullandıkları ilaçlar, motor olmayan semptomların varlığı, Birleşik Parkinson Hastalığı Değerlendirme Ölçeği ve Modifiye Hoehn-Yahr Ölçeği değerleri ve nötrofil/ lenfosit oranları kaydedildi, aralarındaki ilişki araştırıldı.

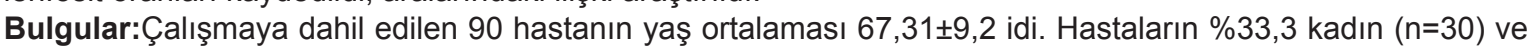
$\% 66,7$ erkek $(n=60)$ idi. Hastalık süresi ortalama 6,91 $\pm 5,06$ yıl idi. Birleşik Parkinson Hastalığı Değerlendirme

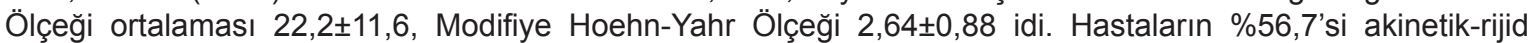
tipte iken, \%43,3'ü ise tremor dominant tipte idi. Hastaların motor olmayan semptomlarından, kabızlık \%57,8, depresyon \%33,3, anosmia \%41,1 ve REM uykusu davranış bozukluğu ise \%57,8'sinde mevcuttu. Hastaların $\% 61,1 ' i$ L-dopa ve dopamin agonisti, \%18,9'u sadece dopamin agonisti, \%17,8'i sadece L-dopa ve \%2,2' si ise sadece MAO-B inhibitörü kullanmakta idi. Hastaların ortalama nötrofil sayısı $(4,54 \pm 1,01) \times 103$, ortalama lenfosit sayısı $(1,97 \pm 0,60) \times 103$ ve nötrofil/lenfosit oranı ise $2,47 \pm 0,82 \mathrm{idi}$.

Sonuç:Nötrofil/lenfosit oranları; Parkinson hastalığı subtipleri, Modifiye Hoehn-Yahr Ölçeği, cinsiyet ve hastalık süreleri ile karşılaştırıldığında istatistiksel olarak anlamlı bir fark saptanmadı. Parkinson hastalığında nörodejenerasyonun gelişiminde periferik inflamasyonun rolü için daha fazla kanıt gerektiren ileri çalışmalara intiyaç vardır.

Anahtar Kelimeler: Parkinson hastalığı, nötrofil/lenfosit oranı, enflamasyon.

Genç F, Erdal A. Parkinson hastalığında nötrofil/lenfosit oranlarının değerlendirilmesi. Pam Tıp Derg 2019;12:297-301.

\begin{abstract}
Purpose: Parkinson's Disease is a neurodegenerative disease that is thought to play a role in the pathogenesis of chronic inflammation. Neutrophil / lymphocyte ratio is a marker of peripheral inflammation. In this study, it was aimed to investigate the relationship between neutrophil/lymphocyte ratio and the stage, duration, and subtypes of Parkinson disease.

Materials and Methods: Ninety patients diagnosed according to the criteria of the United Kingdom Parkinson's Disease Society Brain Bank were retrospectively evaluated demographically. The drugs they were using, the presence of non-motor symptoms, the Unified Parkinson's Disease Rating Scale, the Modified Hoehn-Yahr Scale and neutrophil / lymphocyte ratio were recorded and the relationship between them was investigated.

Results: The mean age of the 90 patients included in the study was $67.31 \pm 9.2$ years. $33.3 \%$ of the patients were female $(n=30)$ and $66.7 \%$ were male $(n=60)$. The mean duration of disease was $6.91 \pm 5.06$ years. The mean Unified Parkinson's Disease Rating Scale was 22.2 \pm 11.6 , Modified Hoehn-Yahr Scale was 2.64 \pm 0.88. $56.7 \%$ of the patients were akinetic-rigid, while $43.3 \%$ were tremor-dominant. Non - motor symptoms of the patients were constipation in $57.8 \%$, depression in $33.3 \%$, anosmia in $41.1 \%$ and REM sleep behavior disorder in $57.8 \%$. $61.1 \%$ of patients were using L-dopa and dopamine agonist, $18.9 \%$ were only dopamine agonists, $17.8 \%$ were using only L-dopa and $2.2 \%$ were using only MAO-B inhibitor. The mean number of neutrophils $(4.54 \pm 1.01) \times 103$, mean lymphocyte number is $(1.97 \pm 0.60) \times 103$ and neutrophil / lymphocyte ratio of the patients were $2.47 \pm 0.82$.

Conclusion: There were no statistically significant difference between neutrophil / lymphocyte ratio and subtypes of Parkinson's Disease, gender, Modified Hoehn-Yahr Scale and duration of Parkinson's Disease. There is a need for further work in Parkinson's Disease that requires further evidence for the role of peripheral inflammation in the development of neurodegeneration.
\end{abstract}

Key Words: Parkinson Disease, neutrophil / lymphocyte ratio, enflammation.

Fatma Genç, Uzm. Dr. SBÜ Antalya Eğitim ve Araştırma Hastanesi Nöroloji Kliniği Varlık Mah. Muratpaşa/ANTALYA, e-posta: sanivardr@ yahoo.com (orcid.org/0000-0002-6062-3694)

Abidin Erdal, Uz.Dr. SBÜ Antalya Eğitim ve Araştırma Hastanesi Nöroloji Kliniği Varlık Mah. Muratpaşa/ANTALYA, e-posta: abidinerdal@ gmail.com (orcid.org/0000-0003-3698-8201) (Sorumlu yazar) 
Genç F, Erdal A. The evaluation of neutrophil/lymphocyte ratio in Parkinson's disease. Pam Med J 2019;12:297301.

\section{Giriş}

Parkinson Hastalığı (PH), substantia nigra (SN) pars compactadaki dopaminerjik nöronların kronik ve ilerleyici kaybı ile karakterize nörodejeneratif bir hastalıktır [1]. Patogenezde; protein agregasyonu, bozulmuş protein yıkım ve kalitesi, mitakondriyal disfonksiyon, bozulmuş kinaz aktivitesi, oksidatif stres ve antioksidan disfonksiyonu düşünülmektedir [2]. Bazı çalışmalarda, hastaların beyinlerinde immünohistokimyasal yöntemlerle reaktif mikroglia ve aktive kompleman bileşenlerinin gösterilmesiyle kronik inflamasyonun da patogenezde önemli bir rolünün olabileceğine dikkat çekmektedir [3]. Aslında merkezi sinir sistemi immünolojik olarak görece korunmuş bir bölge olmasına rağmen yapılan pek çok çalışma sistemik inflamatuar süreçlerin nörodejenereasyonu alevlendirdiğini göstermiştir [4-5]. Nötrofil-lenfosit oranı (NLO) ucuz, kolay uygulanabilir bir periferal inflamasyon göstergesidir [6]. NLO ve PH ile ilgili literatürde çalışma sayısı oldukça az olması nedeniyle bu çalışmada; NLO ile PH' nin evresi, süresi, subtipleri ve cinsiyetler arasındaki ilişkinin araştırılması amaçlanmıştır.

\section{Gereç ve yöntem}

Sağlık Bilimleri Üniversitesi Antalya Eğitim ve Araştırma Hastanesi Nöroloji Kliniği Parkinson Hastalığı ve Hareket Bozuklukları Polikliniği' nde $\mathrm{PH}$ tanısı ile en az 3 ay düzenli takip edilen 90 hasta geriye dönük olarak incelendi. Veriler hasta dosyalarının incelenmesi ile elde edildi. Hastaların sosyo-demografik ve klinik özellikleri, medikal tedavileri, motor olmayan semptomların varlığı, Birleşik Parkinson Hastalığı Değerlendirme Ölçeği (BPHDS), Modifiye Hoehn-Yahr Ölçeği (MHYÖ) değerleri ve nötrofil/lenfosit oranları (NLO) değerlendirildi. NLO'ları, cinsiyet, $\mathrm{PH}$ subtipi, MHYÖ ve hastalık süreleri bağımsız örneklerde t-test ile karşılaştırıldı. Tanımlayıcı istatistik yapıldı. Özet istatistikleri ortalama \pm standart sapma olarak ifade edildi. $P<0,05$ değerleri istatistiksel olarak anlamlı kabul edildi. Tüm istatistiksel analizler Statistical Package for the Social Sciences (SPSS) v20 programı kullanılarak yapıldı.

\section{Bulgular}

Çalışmaya dahil edilen 90 hastanın yaş ortalaması $67,31 \pm 9,2$ idi. Hastaların \%33,3 kadın $(n=30)$ ve $\% 66,7$ erkek $(n=60)$ idi. Hastalık süresi ortalama $6,91 \pm 5,06$ yıl idi. BPHDÖ

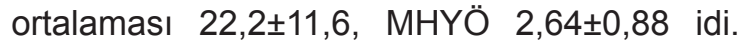
Hastaların \%56,7'si akinetik-rijid tip iken, $\% 43,3$ 'ü ise tremor dominant tipte idi. Hastaların motor olmayan semptomları incelendiğinde, kabızlık \%57,8, depresyon \%33,3, anosmia $\% 41,1$ ve REM uykusu davranış bozukluğu ise \%57,8' sinde mevcuttu (Tablo 1). Hastaların \%61,1'i L-dopa ve dopamin agonisti, \%18,9' u sadece dopamin agonisti, \%17,8' i sadece L-dopa ve \%2,2' si ise sadece MAO-B inhibitörü kullanmakta idi (Şekil 1).

Hastaların ortalama nötrofil sayısı $(4,54 \pm 1,01) \times 10^{3}$, ortalama lenfosit sayısı $(1,97 \pm 0,60) \times 10^{3}$ ve nötrofil/lenfosit oranı ise 2,47 $\pm 0,82$ idi. NLO' ları, akinetik-rijid, tremor dominant gruplar, MHYÖ, cinsiyet ve hastalık süreleri ile karşılaştırıldığında istatistiksel olarak anlamlı fark saptanmadı (Tablo 2).

\section{Tartışma}

Çalışmamızın temel amacı; $\mathrm{PH}$ olan hastalarda cinsiyet, hastalık süresi, hastalık evresi ve Parkinson hastalığı subtipleri ile NLO arasındaki ilişkiyi incelemekti.

Parkinson Hastalığı' nın patogenezinde rol oynadığı düşünülen inflamasyonun mikroglial aktivasyon ve periferal immün hücre infiltrasyonuyla oluştuğu belirtilmiş, ancak aralarındaki ilişki tam olarak açıklanamamıştır [7]. Mikroglialar; santral sinir sisteminde bulunan monosit-makrofaj sistemi kökenli hücelerdir. Genellikle dejeneratif nöronların etrafında yerleşir ve hem dejenerasyon hemde rejenerasyonla ilişkilidirler. Mikrogliayanın en nörotoksik faktörü glutamattır ve yapılan çalışmalar bazı nörodejeneratif hastalıkların hayvan modellerinde, glutamat salınımının azaltılması ile hastalığın ilerlemesi üzerine olumlu etkisi olduğunu göstermiştir. Ayrıca hasar görmüş nöronlar da fraktalkin, interlökin 34 gibi maddeleri salgılayarak çevresindeki mikrogliaların toksik maddeleri fagosite etmesini, antioksidan enzim üretimini arttırmasını sağlayarak kendisini korumaya çalışmaktadır [8]. 
Tablo 1. Çalışmaya alınan hastaların sosyodemografik ve klinik özellikleri.

\begin{tabular}{ll}
\hline Klinik Özellikler & $(\mathbf{n}=90)$ \\
\hline Yaş & $67,31 \pm 9,2$ yıl \\
Cinsiyet & $\% 33,3$ kadın $(\mathrm{n}=30)$ \\
& $\% 66,7$ erkek $(\mathrm{n}=60)$ \\
Hastalık Süresi & $6,91 \pm 5,06$ yıl \\
BPHDÖ & $22,2 \pm 11,6$ \\
MHYÖ & $2,64 \pm 0,88$ \\
PH Subtipi & \\
\multicolumn{1}{c}{ Akinetik-rijit Tip } & $\% 56,7$ \\
\multicolumn{1}{c}{ Tremor-dominant Tip } & $\% 43,3$ \\
Non-motor semptomlar & $\% 57,8$ \\
Konstipasyon & $\% 37,8$ \\
REM Uykusu Davranış Bozukluğu & \\
Anosmi & \\
Depresyon & \\
\hline
\end{tabular}

PH: Parkinson Hastalığı BPHDÖ: Birleşik Parkinson Hastalığı Değerlendirme Ölçeği MHYÖ: Modifiye Hoehn-Yahr Ölçeği

Tablo 2. NLO' larının cinsiyet, hastalık tipi, MHYÖ ve hastalık süresiyle ilişkisi.

\begin{tabular}{llc}
\hline & NLO & $p$ \\
\hline Cinsiyet & $2,2 \pm 0,6$ & \\
Kadın & $2,6 \pm 0,9$ & \\
Erkek & & 0,31 \\
PH Subtipi & $2,4 \pm 0,9$ & \\
Akinetik-Rijit tip & $2,4 \pm 0,7$ & \\
Tremor-Dominant tip & & 0,25 \\
MHYÖ & $2,6 \pm 1,0$ & \\
1-2 & $2,3 \pm 0,6$ & \\
$3-4$ & & 0,15 \\
Hastalık Süresi & $2,6 \pm 0,8$ & \\
$\leq 5 y$ yl & $2,4 \pm 0,8$ & \\
$>5$ yıl &
\end{tabular}

NLO: Nötrofil/lenfosit oranı PH: Parkinson Hastalığı MHYÖ: Modifiye Hoehn-Yahr Ölçeği 


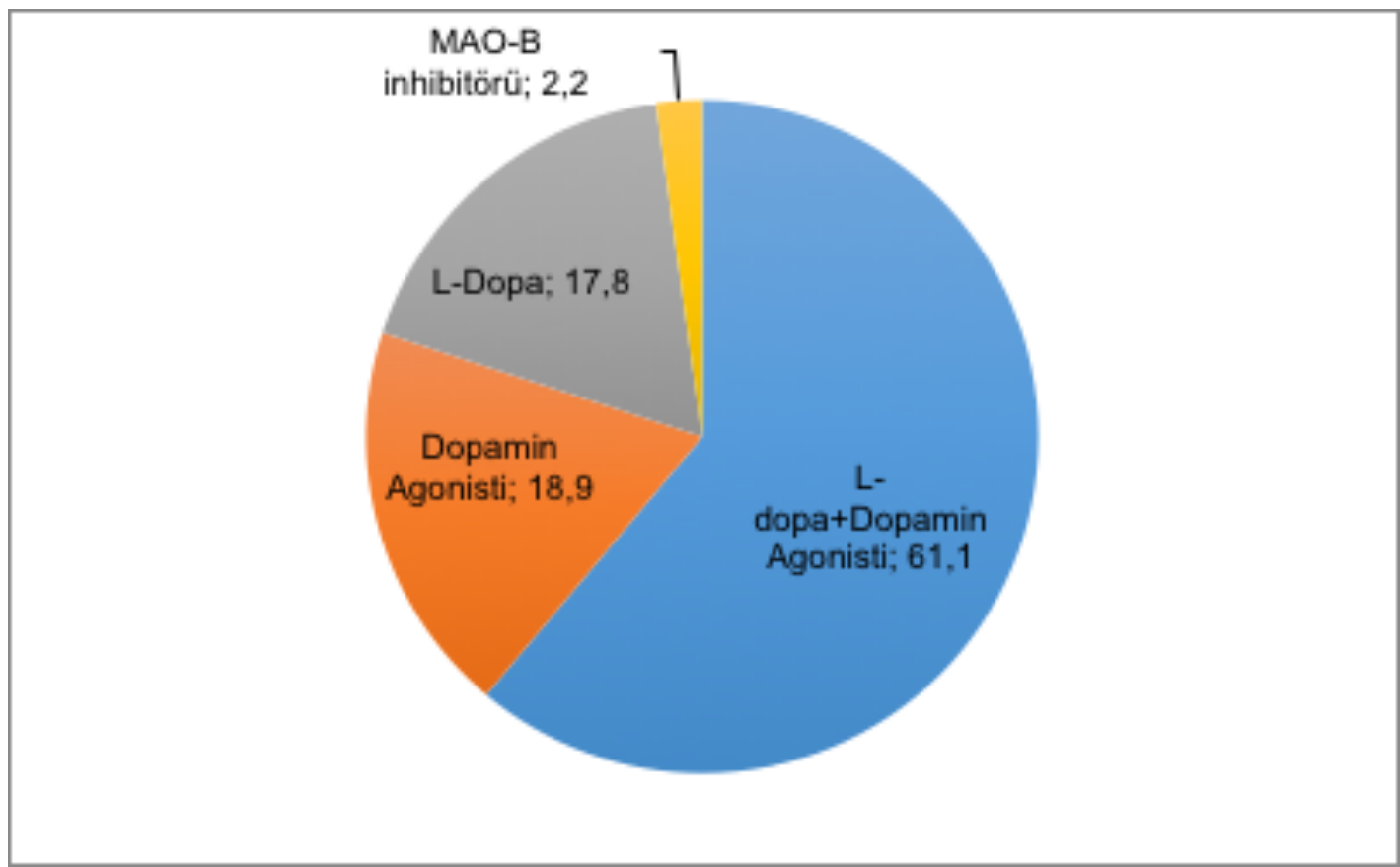

Şekil 1. Tüm hastaların kullandıkları antiparkinson tedavi kullanım oranları.

Hayvan modellerinde ve $\mathrm{PH}$ hastalarında periferal inflamasyonun beyinde devam eden nörodejenerasyonu arttırabileceği öne sürülmüştür [5].

Yapılan bir çalışmada, PH'larının motor subtipleri arasında periferal inflamasyon ve striatal nükleuslardaki DAT (presinaptik dopamin taşıyıcıSı)SPECT (tek foton emisyon tomografisi) değerleri arasındaki ilişki incelenmiş ve NLO'nun tremor dominant PH' larında yaş ve BPHDÖ-III değerleri ile pozitif, Modifiye Schwab England Günlük Yaşam Aktiviteleri Ölçeği skorları ile negatif korelasyonu olduğu bulunmuştur. Ayrıca yine tremor dominant grupta bilateral putamen ve kaudat nükleuslarda ki DAT SPECT görüntülerdeki stiratal bağlanma oranları ve NLO arasında negatif korelasyon gösterilmiştir. Tremor dominant olmayan grupta bu ilişkinin gözlenmemesine de bu iki grup arasında farklı patofizyolojik mekanizmaların olduğunu söyleyerek yorumlamışlardır. Yaptıkları çalışmadaki bulguların; nörodejenerasyon ve inflamasyon arasında bağlantı oluşturarak, periferal inflamasyonun özellikle striatal bölgelerde dopaminerjik kaybın başlamasına ve devam ettirilmesine katkıda bulunabileceğini ileri sürmüşlerdir. Ancak periferal inflamasyon ve $\mathrm{PH}$ progresyonu arasında ki ilişkinin kesin olmadığını da belirtmişlerdir [9].
Kardiyometabolik ve serebrovasküler hastalıklarda NLO'nun arttığı yapılan çalışmalarda gösterilmiş olup, nörodejeneratif bir hastalık olan Alzheimer hastalığı ile ilgili bir çalışmada da benzer ilişki görülmüştür $[6$, 10]. Bizim çalışmamızda ise kontrol grubunun olmaması kısıtlayıcı bir faktör olarak görülebilir ancak çalışmamızın asıl amacı hastalık subtipleri ve NLO arasındaki ilişkiyi incelemektir.

NLO ile PH subgrupları, hastalık süresi ve evresi arasında istatistiksel olarak anlamlı bir fark tespit edilmedi $(p=0,31, p=0,15, p=0,25)$. $\mathrm{Bu}$ bize, klinik ve patolojik olarak birbirinden farklılıkları olan bu subgrupların patogenezinde benzer inflamatuar mekanizmaların rol oynadığını ve inflamasyonun tüm hastalık süresi boyunca devam ettiğini gösterebilir [7]. Ancak yapılan bazı çalışmalarda motor subgruplar arasında fark görülmesi nedeniyle bunu söyleyebilmek için daha fazla invivo ve invitro çalışmaya intiyaç vardır.

Yapılan çalışmalarda, kadınlarda erkeklere oranla daha yüksek düzeyde inflamatuar ve metabolik belirteçler görülse de çalışmamızda kadın ve erkek cinsiyet arasında NLO açısından istatistiksel olarak anlamlı fark görülmemiş, hatta erkek hastalarda NLO seviyesi daha yüksek bulunmuştur $(p=0,06)$. PH'nin erkek cinsiyette daha sık görülmesine neden olan 
faktörlere bağlı olarak böyle bir sonuç çıkmış olabilir [11-13].

Çalışmamızda istatistiksel olarak anlamlı bir fark bulunmasa da, $\mathrm{PH}$ ¿de nörodejenerasyonun gelişiminde periferik inflamasyonun rolü için daha fazla kanıt gerektiren ileri çalışmalara intiyaç vardır.

Çıkar İlişkisi: Yazarlar çıkar ilişkisi olmadığını beyan eder.

\section{Kaynaklar}

1- Tolosa E, Wenning G, Poewe W. The diagnosis of Parkinson's disease. Lancet Neurol 2006;5:75-86.

2- Elibol B. Parkinson hastalığında nöron kaybının moleküler mekanizmaları. In: Elibol B. ed. Hareket bozuklukları 1. baskı. Ankara: Rota Tıp Kitabevi, 2011;101-111.

3- McGeer PL, McGeer EG. Inflammation and neurodegeneration in Parkinson's disease. Parkinsonism Relat Disord 2004;10:3-7.

4- Demir GA. Sinir sistemi infeksiyonları. In: Öge AE, Baykan B. ed. Nöroloji 2. baskı. Nobel Tıp Kitabevleri, 2011;403-421.

5- Ferrari CC, Tarelli R. Parkinson's disease and systemic inflammation. Parkinson's Dis 2011;2011:436813. https://dx.doi.org/10.4061/2011/436813

6- Kuyumcu ME, Yesil Y, Oztürk ZA, ve ark. The evaluation of neutrophil-lymphocyte ratio in Alzheimer's disease. Dement Geriatr Cogn Disord 2012;34:69-74.

7- Ataç Uçar C, Gökçe Çokal B, Ünal Artık HA, İnan LE, Yoldaş TK. Comparison of neutrophil-lymphocyte ratio (NLR) in Parkinson's disease subtypes. Neurol Sci 2017;38:287-293. https://dx.doi.org/10.1007/s10072016-2758-8

8- Suzumura A. Neuron-microglia interaction in neuroinflammation. Curr Protein Pept Sci 2013;14:1620.

9- Sanjari Moghaddam H, Ghazi Sherbaf F, Mojtahed Zadeh M, Ashraf-Ganjouei A, Aarabi MH. Association between peripheral inflammation and DATSCAN data of the striatal nuclei in different motor subtypes of Parkinson Disease. Front Neurol 2018;9:234. https:// dx.doi.org/10.3389/fneur.2018.00234

10- Akıl E, Bulut A, Kaplan I, Özdemir HH, Arslan D, Aluçlu MU. The increase of carcinoembryonic antigen (CEA), high-sensitivity C-reactive protein, and neutrophil/ lymphocyte ratio in Parkinson's disease. Neurol Sci 2015;36:423-428. https://dx.doi.org/10.1007/s10072014-1976-1

11- Gaines J, Vgontzas AN, Fernandez-Mendoza J, Kritikou I, Basta M, Bixler EO. Gender differences in the association of sleep apnea and inflammation. Brain Behav Immun 2015;47:211-217. https://dx.doi. org/10.1016/j.bbi.2014.11.013
12- Everett BG, Rosario M, McLaughlin KA, Austin SB. Sexual orientation and gender differences in markers of inflammation and immune functioning. Ann Behav Med 2014;47:57-70. https://dx.doi.org/10.1007/ s12160-013-9567-6

13- Kieburtz K, Wunderle KB. Parkinson's disease: evidence for environmental risk factors. Mov Disord 2013;28:813. https://dx.doi.org/10.1002/mds.25150

Bu çalışma, 28 Nisan 2018' de 3. Akyaka Nöroloji Günleri' nde Uzm. Dr. Fatma Genç tarafından sözel bildiri olarak sunulmuştur. 